\title{
Entrevista de Antonio Candido sobre Jurandir Ferreira
}

\author{
Ludmila Menezes Zwick*
}

Sua alma é altruísta e modesta, condescendente e discreta [...] essas qualidades nada trazem de bom ao indivíduo que as possui, visto como, por serem tão extraordinárias, passam sempre como coisas absurdas às quais os homens que se consideram esclarecidos jamais prestam a menor atenção. As qualidades realmente superiores são inacreditáveis ou todos procuram obscurecê-las, quando não procuram tirar delas o melhor partido para si (FERREIRA, 1972, p. 99).

A força real e verdadeira está no coração e na palavra dos bons. Com ela todos os prodígios são realizáveis. Até mesmo esse milagre de salvar o Brasil, tão inverossímil, tão escandaloso, mesmo como simples enunciação de uma probabilidade remota (FERREIRA, 1991, p. 36).

Muitos dos aspectos primitivos e das belas condições de vida em Poços de Caldas o boi bebeu e estão bebidos para sempre (FERREIRA, 1991, p. 245).

Mestre em Estética e História da Arte e doutora em Literatura e Cultura Russa pela Universidade de São Paulo (USP). 


\section{Apresentação}

Era ainda o período em que, para mim, o senhor Antonio Candido integrava apenas o restrito conjunto de pessoas ${ }^{1}$ a quem entrevistei para minha pesquisa de iniciação científica acerca do escritor poços-caldense Jurandir Ferreira (1905-1997). ${ }^{2}$ Assim sendo, conversei com ele tal como vinha fazendo com os demais entrevistados, quase todos pertencentes à sua geração; alguns deles, caros amigos seus, caso de Resk Frayha (1915-2008).

Num finzinho de tarde do início de 2001, toca o telefone em minha casa, em Poços de Caldas; era o próprio senhor Antonio Candido. Eu já havia agendado a visita a ele, em São Paulo, e ele havia ligado porque percebera que não me seria fácil chegar ao endereço que me indicara (nesse período, estudantes como eu não tinham computador pessoal e somente pouco acesso à internet, e eu havia ido a São Paulo apenas uma única vez com outros estudantes a fim de visitar o Museu do Ipiranga). Disse-me, pois, para apanhar papel e caneta e anotar cada pormenor - as estações do metrô e as ruas que levariam à sua casa. Tratava-se de um tipo de generosidade e percepção muito próprias a todos os que eu estava entrevistando naquele período. Pouco tempo depois, com

1 Além de Antonio Candido, entrevistei Graciema Ferreira (irmã de Jurandir), o médico Benedicto Cauby Ferreira (sobrinho do autor), o engenheiro de minas Resk Frayha, o escritor Chico Lopes, as professoras Olga e Beatriz Monteiro (primas da esposa de Jurandir), Marcos Vinícius de Moraes (da Academia Poços-caldense de Letras), o médico Benedictus Mário Mourão e o historiador Odilon Nogueira de Matos. Geralmente à tarde, seguia sozinha, munida de um pequeno gravador, para obter informações sobre Jurandir Ferreira; cada entrevistado preencheu pelo menos uma fitinha cassete. Com a maioria deles estive em mais de uma ocasião e, visto que todos possuíam conhecimentos substanciais sobre muitos assuntos, nossas conversas foram, para mim, muito enriquecedoras. Apesar da distância de gerações, alguns dos entrevistados se tornaram meus amigos; cito, em especial, dona Graciema.

2 A respeito do autor, há o trabalho de referência e fôlego Viana (2007). 
genuíno refinamento, o senhor Antonio Candido recebeu-nos em São Paulo (nesse caso, meu orientador, o professor Gérson Pereira Filho, fez questão de me acompanhar), ocasião em que me deu quatro de seus livros, autografando um deles, sem que eu chegasse a solicitá-lo.

Passados alguns meses, recebo outro telefonema, era o senhor Antonio Candido me informando que estava em Poços e que, como havia combinado, me avisava para que continuássemos a conversa. Tanto em Poços como na vez anterior em São Paulo, falamos um par de horas, tarde afora; eu, sem qualquer traquejo acadêmico. Falamos sobre política e sobre autores mineiros, sobre autores como Euclides da Cunha e sobre o Rio Pardo, e, claro, também sobre Jurandir Ferreira. Não gravei ou filmei essas conversas, coisa que nem me ocorreu. Mais tarde compreendi que ele ouvia as opiniões literárias de uma jovem com intuito de fazer o que faz o bom professor: aproximar o leitor do autor, não tornar a literatura algo inalcançável. Ouvia sem qualquer vestígio de desdém aquelas minhas observações de leitora comum. Falamos também de pessoas que ambos conhecíamos, sem que essas conversas ainda tivessem relação com a entrevista apresentada aqui, feita via correspondência, já que Antonio Candido preferiu responder por escrito.

Naquele tempo, meu fascínio ainda ingênuo me fazia perambular pelos arquivos de Poços de Caldas; frequentava o acervo do Museu Histórico e Geográfico para ler os jornais com as crônicas de Jurandir Ferreira - pretendia traçar um roteiro turístico extraído de sua obra - e consultava variados documentos, como os das Thermas Antonio Carlos. Lá, certa tarde, depareime com um documento referente ao pai do professor Antonio Candido, Aristides Mello e Souza. No documento, porém, 
constava Aristides Souza e Mello, do que deduzi que seria essa, então, a ordem correta dos sobrenomes de Antonio Candido. Ao me dar conta do equívoco, tratei de esclarecê-lo, mas o professor já enviara a resposta a minhas perguntas, na qual constava: "Anote que o meu sobrenome é Mello e Souza, não Souza e Mello. Mas, curiosamente, você deu sem querer a versão correta. O pai de meu bisavô se chamava Souza Mello, mas ali pela altura da Independência, ocorreu uma inversão, não se sabe por que... De modo que ao errar você acertou". Mais tarde, em conversa, ele ainda brincou com esse acerto do meu erro.

\section{Figura 1. Última página da carta}
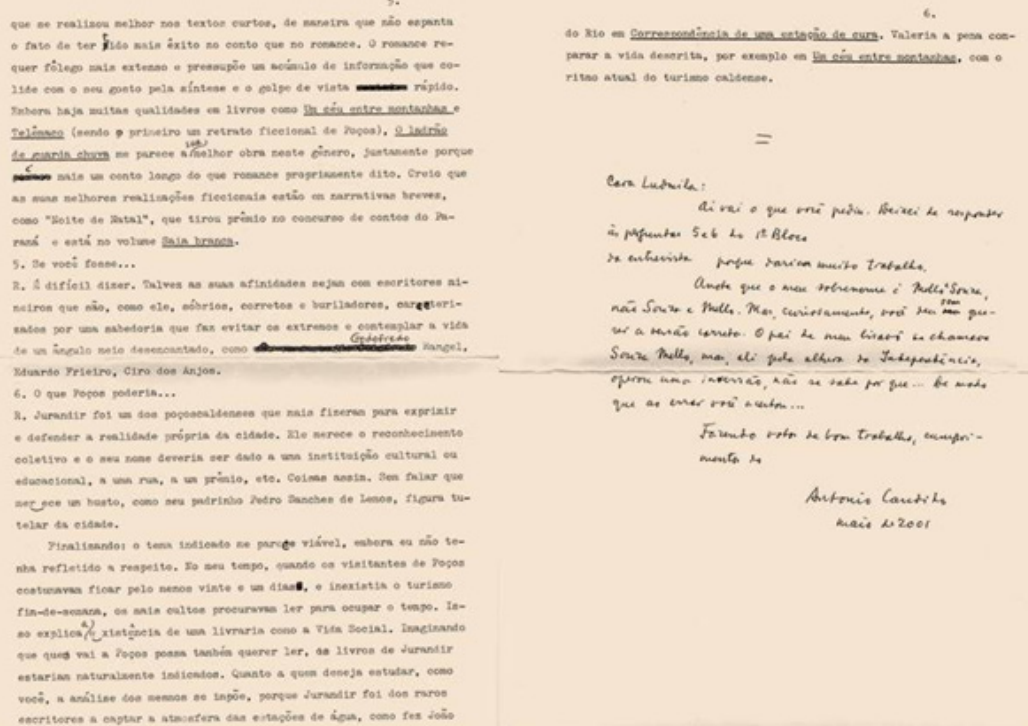

Fonte: Acervo pessoal 


\section{Transcrição da entrevista datilografada}

\section{Primeiro bloco}

Ludmila Menezes Zwick: Fale sobre sua relação e de sua família com a cidade de Poços de Caldas:

Antonio Candido: Meu avô materno, José de Carvalho Tolentino, médico no Rio, foi um dos sócios da Empresa que arrendou do governo de Minas a exploração das águas de Poços de Caldas, e que transformou o pequeno povoado em estação termal a partir de 1882. Ele morou em Poços com a família no período em que foi diretor, nos anos de 1880 e, depois, de 1891 a 1896, quando terminou a construção do segundo balneário (Macacos), vendeu as suas ações (era o maior acionista) e voltou ao Rio, morrendo logo depois. Minha mãe nasceu em Poços no ano de 1893. Por coincidência, quando o governo de Minas resolveu explorar diretamente as águas e efetuou a grande transformação da cidade a partir de 1926, sob a direção de Carlos Pinheiro Chagas, meu pai, Aristides de Mello e Souza, que clinicava na sua terra, Cássia, no Sudoeste de Minas, foi contratado para dirigir os novos serviços termais, de modo que veio a fazer mais ou menos o mesmo que meu avô fizera em caráter privado. Ele dirigiu as termas de 1930 a 1936 e a seguir voltou à clínica particular. Chegamos a Poços em janeiro de 1930, ele morreu no começo de 1942, mas conservamos a casa e sempre a frequentamos, até vendê-la em 1989, tendo-a, portanto, ocupado por quase sessenta anos. Como vê, a nossa ligação com Poços durou mais de um século. 
Ludmila Menezes Zwick: Descreva a visão de Poços de Caldas em seus vários aspectos de quando o Sr. ali viveu:

Antonio Candido: Poços era uma pequena cidade encantadora quando chegamos. Tinha 12 mil habitantes e um ritmo agradável: nos meses de "estação", quando vinham os "banhistas", como se dizia, ficava movimentada, cheia de gente de fora, figurões, grã-finos, moças e rapazes alegres que enchiam os hotéis, dançavam, passeavam. O jogo movimentava tudo, havia orquestras e salas de baile, concursos hípicos, corridas de automóveis, etc. Isso, mais ou menos de dezembro a abril. No resto do ano, pouco movimento, vida pacata, num ambiente bonito entre os morros. Era um mundo incomparável para jovens como eu e meus amigos, mas para os pobres podia ser muito duro nos meses do chamado "intervalo", quando os que viviam do movimento de forasteiros ficavam sem meios de ganhar a vida. Nós tínhamos em casa um termômetro disso, pois então apareciam meninos e rapazinhos pedindo alimento e minha mãe lhes fornecia diariamente de 6 a 8 almoços servidos no terraço. Mas quando começava a "estação" e suas oportunidades, todos desapareciam e só voltavam no próximo "intervalo".

Ludmila Menezes Zwick: Viver em Poços influenciou de alguma forma sua carreira acadêmica e literária? Como?

Antonio Candido: Para mim, viver em Poços foi antes de mais nada viver na casa de meus pais, retirada então do centro, favorável ao tipo de vida que levávamos, com poucas relações e muito convívio íntimo. Meus pais tinham uma biblioteca (em parte doada para a Faculdade de Poços) e se preocupavam em 
nos iniciar nos conhecimentos literários, históricos e científicos. Além disso, havia na cidade uma livraria notável, a Vida Social, na rua Bahia, atual Prefeito Chagas, onde era possível comprar não apenas livros brasileiros, mas também franceses e ingleses. Era uma verdadeira mina, porque meu pai nos deixava comprar à vontade. Devo dizer também que o colégio onde estudamos, e depois foi dado aos maristas, era modesto, mas estimulante, e nele tive alguns ótimos professores, dos quais quero mencionar Edmundo Gouveia Cardillo, grande mestre do português, e dona Maria Ovídia Junqueira, senhora de grande cultura, que me iniciou na bibliografia de língua inglesa e exerceu sobre mim grande influência. A minha adolescência em Poços foi muito agradável. E até 1989 a nossa casa continuou para mim um lugar de estudo e trabalho intelectual, com a sua biblioteca e por assim dizer a inspiração de meus pais. Como eu passava nela as férias e ia frequentemente durante o período letivo, às vezes todos os fins de semana, creio que, somando tudo, ficava anualmente em Poços de 3 a 4 meses.

Ludmila Menezes Zwick: O Sr. soube que a casa em que residiu sua família na Rua Capitão Afonso Junqueira em Poços de Caldas foi demolida, embora houvessem iniciativas para preservá-la como patrimônio cultural? O que pensa sobre isso?

Antonio Candido: Soube e não fiquei abalado. Ela estava tão maltratada e desfigurada, que quando recebi a notícia senti certo alívio, como se fosse a morte libertadora, pondo um termo ao seu martírio. 


\section{Segundo bloco}

Ludmila Menezes Zwick: Como foi seu relacionamento com o escritor poços-caldense Jurandir Ferreira?

Antonio Candido: Lembro de Jurandir desde 1930, quando fomos morar em Poços. Ele trabalhava na Farmácia Santa Teresinha, de Martinho Mourão, na rua Junqueiras, e logo depois fundou a Farmácia Rosário, na rua então denominada Paraná, atual Assis Figueiredo, esquina de Pernambuco. Mais tarde vendeu-a e estabeleceu um laboratório de análises. Durante muito tempo só o conheci de vista, inclusive porque era bem mais velho do que eu. Guardo a lembrança de ver na rua um rapaz discreto, de ar severo e concentrado, muito elegante, vivendo meio à parte com a sua senhora, a benemérita Elza Monteiro Ferreira. Lembro também que sempre teve preocupação com assistência social, tanto assim que idealizou a Gota de Leite, ideia assumida pelo prefeito Figueiredo e realizada a seu pedido por dona Maria Ovídia Junqueira à frente de um grupo de senhoras, entre as quais minha mãe, Clarice Tolentino de Mello e Souza. Mais tarde Elza e Jurandir criaram o S.O.S., organização que foi realmente exemplar. Só comecei a ter relações com eles quando minha família já não morava na cidade, depois da morte do meu pai em 1942. Creio que Elza e Jurandir se interessaram por mim quando me tornei crítico literário da Folha da Manhã, em 1943. Nas férias de julho de 1944 me procuraram e a partir de então formamos uma boa amizade, que durou enquanto viveram, com muito afeto recíproco. Eu os via geralmente nas estadias mais longas do período de férias. Devo dizer que essas relações tinham um precedente: o maior amigo de Jurandir, se não me 
engano, foi meu primo João de Mello Macedo, bom poeta e seu colega na Faculdade de Farmácia de Pouso Alegre. Por falar em parentesco, acho oportuno dizer que Jurandir tinha um primo muito culto e inteligente, Leopoldo Ferreira, que morreu relativamente moço. Com pseudônimo de Leo Ferrer, ele fazia semanalmente uma crônica denominada "Prosa Bárbara" no jornal Revista de Poços de Caldas. Isso foi na primeira metade dos anos de 1930.

Ludmila Menezes Zwick: Fale sobre Jurandir Ferreira, a pessoa, o amigo:

Antonio Candido: Jurandir era um homem finíssimo, discreto, que ouvia com muita deferência e falava de maneira natural, pausada e serena. Era de aspecto tranquilo e equilibrado, mas de temperamento forte, e muito decidido quando se tratava de afirmar os seus pontos de vista. Amava profundamente a sua cidade e procurava defendê-la pela ação e a escrita sempre que houvesse ameaça à sua integridade e ao teor da sua vida. Assim foi que escreveu com veemência contra o teleférico, o calamitoso e acintoso monotrilho, o abuso desnecessário de prédios altos e muita coisa mais, como se pode ver nas suas crônicas. O seu convívio era um raro prazer.

Ludmila Menezes Zwick: Fale sobre Jurandir Ferreira, o escritor:

Antonio Candido: Jurandir era um mestre da língua. Pouca gente a usou tão bem, com tanta correção, elegância 
e expressividade. Pertencia à família dos buriladores, que consagram um esforço tenaz para conseguir a expressão exata e bem torneada. Isso tinha raízes na sua extensa cultura, começada desde muito moço e desenvolvida pela vida afora por meio de leituras constantes. A sua obra tem vários aspectos e vários níveis. Eu diria, simplificando, que foi poeta e romancista apreciável, contista de muita qualidade e verdadeiro mestre da crônica. Creio que uma de suas forças foi não ter ficado escravo das modas literárias. Ele formou a sua maneira própria desde bem moço, com base nos escritores clássicos e nos que eram modernos no começo do século. Por meio deles forjou um estilo sem compromissos de escola, capaz de manifestar a sua visão do mundo e dos seres.

Ludmila Menezes Zwick: Sabemos que Jurandir Ferreira sempre oferecia ao Sr. seus livros autografados, como prova de amizade e confiança em sua crítica. Quais livros dele o Sr. considera mais valiosos do ponto de vista literário?

Antonio Candido: Ficou implícito no que acabo de dizer que acho as crônicas a sua produção mais sólida. A crônica é um gênero muito brasileiro, com praticantes de alta qualidade, desde Machado de Assis e Olavo Bilac até Rubem Braga e Rachel de Queiroz, sem falar nos grandes poetas modernistas: Manuel Bandeira, Mário de Andrade, Carlos Drummond. Jurandir se enquadra honrosamente nessa linha, porque soube usar a nota breve para transmitir mensagens condensadas, elegantes e sugestivas. Neste terreno, repito, é de fato magistral. Essas observações sugerem que se realizou melhor nos textos curtos, de maneira que não espanta o fato de ter tido mais êxito no conto que no romance. $\mathrm{O}$ romance requer fôlego mais extenso e pressupõe 
um acúmulo de informação que colide com o seu gosto pela síntese e o golpe de vista rápido. Embora haja muitas qualidades em livros como $\mathbf{O}$ céu entre montanhas e Telêmaco (sendo o primeiro um retrato ficcional de Poços), Um ladrão de guardachuvas me parece a sua melhor obra nesse gênero, justamente porque é mais um conto longo do que romance propriamente dito. Creio que as suas melhores realizações ficcionais estão em narrativas breves, como "Noite de Natal", ${ }^{3}$ que tirou prêmio no concurso de contos do Paraná ${ }^{4}$ e está no volume Saia branca.

Ludmila Menezes Zwick: Se fosse estabelecer um paralelo entre Jurandir e outro representante da literatura brasileira, com qual seria?

Antonio Candido: É difícil dizer. Talvez as suas afinidades sejam com escritores mineiros que são, como ele, sóbrios, corretos e buriladores, caracterizados por uma sabedoria que faz evitar os extremos e contemplar a vida de um ângulo meio desencantado, como Godofredo Rangel, Eduardo Frieiro, Ciro dos Anjos.

Ludmila Menezes Zwick: O que Poços de Caldas poderia fazer para prestar um justo reconhecimento a Jurandir Ferreira? Em sua opinião, acha viável o vínculo entre turismo e literatura, o turismo literário?

3 Passado o tempo, pude perceber em conversa com o senhor Antonio Candido que o conto em questão na verdade chama-se "As estrelas".

4 Primeiro Concurso Nacional de Contos, realizado em Curitiba, em 1968. Ao lado de contos de autores como Lygia Fagundes Telles, Ignácio de Loyola Brandão, Flávio José Cardozo, Luiz Vilela e Dalton Trevisan, o texto de Jurandir Ferreira foi publicado naquele mesmo ano no volume Os 18 melhores contos do Brasil. 
Antonio Candido: Jurandir foi um dos poços-caldenses que mais fizeram para exprimir e defender a realidade própria da cidade. Ele merece o reconhecimento coletivo e o seu nome deveria ser dado a uma instituição cultural ou educacional, a uma rua, a um prêmio, etc. ${ }^{5}$ Coisas assim. Sem falar que merece um busto, como seu padrinho Pedro Sanches de Lemos, figura tutelar da cidade.

Finalizando: o tema indicado me parece viável, embora eu não tenha refletido a respeito. No meu tempo, quando os visitantes de Poços costumavam ficar pelo menos vinte e um dias, e inexistia o turismo fim-de-semana, os mais cultos procuravam ler para ocupar o tempo. Isso explica a existência de uma livraria como a Vida Social. Imaginando que quem vai a Poços possa também querer ler, os livros de Jurandir estariam naturalmente indicados.

Quanto a quem deseja estudar, como você, a análise dos mesmos se impõe, porque Jurandir foi um dos raros escritores a captar a atmosfera das estações de água, como fez João do Rio em Correspondência de uma estação de cura. Valeria a pena comparar a vida descrita, por exemplo em Um céu entre montanhas, com o ritmo atual do turismo caldense.

5 Na ocasião ainda não havia sido inaugurada a Biblioteca Jurandir Ferreira, no Instituto Moreira Salles. Além da biblioteca pessoal, o autor deixou documentos como as correspondências com Carlos Drummond de Andrade, Érico Veríssimo, André Maurois, Anatole France e com o próprio Antonio Candido. 


\section{Referências}

CANDIDO, Antonio. Jurandir Ferreira. Poços de Caldas-São Paulo, mai. 2001. Entrevista concedida a Ludmila Menezes Zwick. 6 p. datilografadas. Não publicada.

FERREIRA, Jurandir. Saia branca. São Paulo: Duas Cidades, 1972.

FERREIRA, Jurandir. Da quieta substância dos dias. São Paulo: Instituto Moreira Salles, 1991.

VIANA, Huendel Junio. Jurandir Ferreira: o escritor escondido - biografia, seleção de textos e catálogo bibliográfico. 2007. Dissertação (Mestrado em Teoria Literária e Literatura Comparada) - Faculdade de Filosofia, Letras e Ciências Humanas, Universidade de São Paulo, São Paulo, 2007. doi:10.11606/D.8.2007.tde-22052007-135951. Acesso em: 20 nov. 2019. 